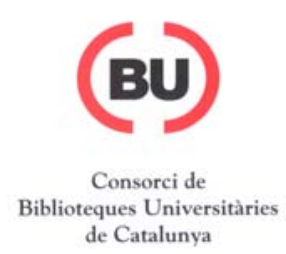

\title{
Collaborations and alliances: social intelligence applied to academic libraries
}

Lluís M. Anglada i de Ferrer

(Consortium of Academic Libraries of Catalonia)

\begin{abstract}
Purpose - This article analyzes the different forms of library cooperation and the different types of relations that can be established for collaboration among libraries.

Design/methodologylapproach - The author attempt to show how cooperation as an application of the social intelligence is a tool to improve library services. For that, he use the situation of Spanish university libraries between 1980 and 2005. Adopting an evolutionary approach, the author shows how cooperation has affected library organizations, and concludes that the current situation shows an intelligent adaptation to the needs of society.
\end{abstract}

Findings - Using the evolution of the academic libraries in Spain between 1980 and 2005 , the article analyzes six different forms of relation or cooperation that can be established by libraries. Those are: companionship, collaboration, association, cooperation, alliances and fraternization. The author attempt to provide some guidelines for cooperation that may be of value to university libraries in their path towards the future. The approach is global, systemic and evolutionary. It is global in the sense that Spanish university libraries are taken as a model for exemplifying trends that are applicable to all types of libraries all over the world. It is systemic in the sense that it sees the Spanish case as one of a wide range of processes that do not occur in isolation in a world in which libraries_even at an international level-form part of a whole. Finally, it is evolutionary in the sense that it considers that the future will be built on our current achievements, which in turn depended on those of the past.

Originality/value - The development of individual living beings and species depends to a large extent on their ability to cooperate. Similarly, the development of organizations and groups of organizations depends on their ability to work together and to establish a framework in which individual goals are attained thanks to external achievements or situations. Libraries are no exception to this, and may in fact serve as a paradigmatic example. Throughout history they have tended to develop powerful mechanisms of cooperation.

Keywords - Academic libraries, Universities, Strategic alliances, Spain

Paper type - Research paper 


\begin{abstract}
"There are intelligent couples and stupid couples, intelligent families and stupid families, intelligent societies and stupid societies. The criterion is always the same: intelligent groups gather information better, i.e. they adapt better to reality, perceive the problems earlier, invent effective solutions and put them into practice. Thus, in addition to personal intelligence (which can be used privately or publicly) we find social intelligence" ${ }^{1}$
\end{abstract}

\title{
1. Introduction: viewpoints and definitions
}

The development of individual living beings and species depends to a large extent on their ability to cooperate. Similarly, the development of organizations and groups of organizations depends on their ability to work together and to establish a framework in which individual goals are attained thanks to external achievements or situations. Libraries are no exception to this, and may in fact serve as a paradigmatic example. Throughout history they have tended to develop powerful mechanisms of cooperation because they are mainly public sector institutions with a vocation of providing services.

In this article I will attempt to provide some guidelines for cooperation that may be of value to Spanish university libraries in their path towards the future. The approach I have taken is global, systemic and evolutionary. It is global in the sense that Spanish university libraries are taken as a model for exemplifying trends that are applicable to all types of libraries all over the world. ${ }^{2}$ It is systemic in the sense that it sees the Spanish case as one of a wide range of processes that do not occur in isolation in a world in which libraries-even at an international level-form part of a whole. Finally, it is evolutionary in the sense that it considers that the future will be built on our current achievements, which in turn depended on those of the past. This approach is based on the belief that, though some stages in evolution may be compressed in time, one cannot normally reach a given level without previously going through all the earlier ones.

We will now define some terms that will be useful for analyzing the different forms of relation or cooperation that can (and must) be established by university libraries (and of course other ones) in Spain:

- Companionship refers to the spirit of teamwork that develops within the library (whether it is a physical library or a university library operating as a service within a university).

- Collaboration refers to the relations that the library establishes with other services within the university or, at a lower level, within the faculty or campus.

- Association refers to the links established with libraries located in the same sphere, whether geographic, of type (e.g. university libraries) or of specialty (e.g. architecture libraries).

- Cooperation refers to links that are now stronger than the above ones because not only ideas but also resources are shared. In the course of this article I think this differentiation will be seen to be useful.

\footnotetext{
${ }^{1}$ José A. Marina / La inteligencia fracasada: teoría y práctica de la estupidez. Barcelona, Anagrama, 2004

${ }^{2} \mathrm{~A}$ preliminary version of this article was drawn up as a contribution to the debate on the new Strategic Plan of REBIUN (the Spanish association of directors of academic libraries). Obviously, in that context the references focused on university libraries, though without considering that they were the only ones that could generate social intelligence.
} 
- Alliances refer to the relations established with organizations that have different natures and aims but partially coinciding objectives.

- Fraternization refers to the links established with organizations of the same type and nature in other countries.

The above categories represent different types of social intelligence. They are extremely hierarchical in the sense that it is difficult to establish collaboration with other services within the university if the library itself has not developed a spirit of companionship that makes it a unit, and it is difficult to form alliances without first having formed associations.

\section{Social intelligence and libraries}

The traditional definition of intelligence is based on psychometric tests that assess a person's ability to solve a theoretical problem. Understood thus, intelligence was an absolute value that could be complemented with other human faculties that were called skills, gifts, talents, abilities or aptitudes. Howard Gardner was the first to speak of multiple intelligences in $1983^{3}$. In a more recent work ${ }^{4}$ he defines intelligence as "a biopsychological potential to process information that can be activated in a cultural setting to solve problems or create products that are of value in a culture". He recognizes seven original intelligences, including 'interpersonal intelligence', which he defines as "[a person's] capacity to understand the intentions, motivations, and desires of other people and, consequently to work effectively with others."

Other authors have established a smaller or larger set of basic intelligences than Gardner or have popularized some types, particularly emotional intelligence. ${ }^{6}$ Albrecht used the term social intelligence instead of interpersonal intelligence and defined it as "a combination of basic understanding of people [...] and a set of component skills for interacting successfully with them". ${ }^{7}$ Goleman $^{8}$ states that some interaction skills (e.g. the ability to manipulate) should not be considered as forming part of social intelligence, which not only implies a knowledge of the functioning of relations but also intelligent behavior within them.

Social intelligence has played an important role in the development of libraries, in which success or failure have often depended on the accumulated capital of social intelligence. For example, software that has been successfully implemented in one library has failed in another, even though there are no substantial differences in their syllabuses. The

\footnotetext{
${ }^{3}$ Howard Gardner / Frames of mind: the theory of multiple intelligences (New York: Basic Books, 1983).

${ }^{4}$ Howard Gardner / La inteligencia reformulada: las inteligencias múltiples en el siglo XXI (Barcelona: Paidós, 2001), p. 45. Original ed.: Intelligence reframed (New York: Basic Books, 1999).

5 Ibid. p. 53. My italics.

${ }^{6}$ Daniel Goleman / Inteligencia emocional (Barcelona: Kairós, 1996). Original ed.: Emotional intelligence (New York: Bantam Boks, 1995)

Karl Albrecht / Inteligencia social (Barcelona: Vergara, 2006), p. 22. Original ed.: Social intelligence (Chichester: John Wiley \& Sons, 2006.

8 Daniel Goleman / Inteligenca social: la nueva ciencia de las relaciones humanas (Barcelona: Kairós, 2006), p. 24-25. Original ed.: Social intelligence (New York: Bantam Books, 2006).
} 
collective social intelligence that is at play in the successful library may go a long way towards explaining such differences in development.

\section{Where we come from}

In the last 25 years Spanish university libraries have developed through collaboration: as a result of teamwork (sometimes informal), advances in one place and time have been possible thanks to earlier, perhaps smaller, advances elsewhere. The current level of library services in Spanish universities has been reached thanks to work based on benchmarking and mutual support. ${ }^{9}$ Several stages of development of Spanish university libraries can be distinguished

Elsewhere $^{10}$ it has been stated that since the 1980s Spanish university libraries have gone through three stages of evolution. These can be summarized as follows:

- From university libraries to the university library. This stage lasted until the early 1990s. It marked a reaction to the dispersion of libraries and the low quality of services. Effective management of library services was consolidated, technical services were set up and operations were centralized.

- From the university library to the university library system. This stage began in the mid-1990s and marked the maturity of the university library system. It was a reaction to the previous model characterized perhaps by excessive rigidity and theoretical approaches that were not adapted to the Spanish context. Personnel structures were organized, attention was shifted from the activities of libraries to users and services, and the technical services were redefined.

- From the university library system to a service complementary to university teaching and research. This stage began with the new century and is still underway. It is now necessary to adopt a new role by adapting to two profound changes: the new context of higher education in Europe and the possibilities of electronic information. The current challenges are to increase the use of information in all areas of university life, to make library organization more flexible, and to adopt new roles within universities. ${ }^{11}$

From the evolutionary viewpoint, the current situation cannot be understood without going back to the initial situation, which has affected everything that has happened in the intervening period. We will now present a simplified outline of the relational scenario of Spanish university libraries only a few years ago.

Let us go back to the early 1990s. What we have called companionship existed but was a recent development. The tradition of university libraries until then (perhaps with a few honorable exceptions) was to divide them into many points of service that were not seen as a unit by either the university community or the staff of the libraries. As there was no single university library, there was also no collaboration with other services.

\footnotetext{
$9 \quad$ Lluís Anglada, Margarita Taladriz / Pasado, presente y futuro de las bibliotecas universitarias españolas // Arbor, 157 (1997) 617-618, pp. 65-88.

10 Lluís Anglada / Canvis i reptes organitzatius a les biblioteques universitaries // Item 23(98), pp. 32-48.

${ }^{11}$ Wendy Pradt Lougee / Diffuse libraries: emergent roles for the research library in the digital age // Washington: Council on Library and Information Resources, Nov. 2003 http://www.clir.org/pubs/reports/pub108/pub108.pdf
} 
Association was weak. In the $1980 \mathrm{~s}$, the focus had been on specialization: ${ }^{12}$ the association of biomedical libraries (CCDB) was set up in 1983, the association of mathematical academic libraries (Documat) was set up in 1988, the association of architecture libraries (ABBA) was set up in 1991 and the association specialized in engineering (MECANO) was set up in 1995. An important role was also played between 1990 and 1995 by the user groups of the automated systems used in Spanish universities (the international systems, Dobis/Libis, Libertas and VTLS, and the Spanish system, Absys). The importance of these groups decreased when the automation programs went beyond the implementation stage. The Spanish association of directors of academic libraries (REBIUN: Red Española de Bibliotecas UNiversitaras) began to operate in the late 1980s, and two of its most important contributions to Spanish university libraries date from that time: the collective catalogue and interlibrary loan. However, REBIUN was then a small association that included only a relatively small number of libraries. Its transformation into a national association came later.

REBIUN was created in the cooperative spirit of the library networks that had been set up in the 1970s and 1980s. Its initial approach was perhaps similar to that of the cooperatives created in the United States and the United Kingdom, but it later evolved to become an association. The Conference of Directors of Spanish University and Science Libraries (CODIBUCE), which had a short but fruitful life, carried out actions that can be considered as establishment of alliances. It attempted and sometimes managed to establish collaboration programs with the Spanish Council of Universities (for statistics), the academic telecommunication network (Red Iris) and the Assistant Directorate-General for Public Libraries of the Ministry of Culture. There is little to be said here about what I have defined as fraternization, because contacts and relations with libraries in other countries were almost non-existent.

\section{Where the world is going}

Just as the animal world does not evolve without increasing the complexity of living organisms, the social world and organizations do not evolve without increasing the density of their relations. Manuel Castells claims that one of the most profound changes that our society is undergoing is in the way it does things. He sets the 'tree' society against the 'network' society. ${ }^{13}$ In the tree society, developed in the 19th and 20th centuries, organizations take the form of large, hierarchically organized conglomerates, with a head and many parts that are highly specialized and isolated.

In the network society, which has been taking shape for some years and will be the dominant form in this century, organizations will not be large in size, and neither they nor their parts will be 'autarchic'. The organizations in the network society are divided into

\footnotetext{
${ }^{12}$ Lluís Anglada, 'Cooperació bibliotecària a Espanya', in: Item (January-June 1995) №. 16, pp. 51-67 and José Antonio Merlo Vega, 'La cooperación en las bibliotecas universitarias: fundamentos y redes cooperativas', in: Boletín de la Asociación Andaluza de Bibliotecarios, 54 (January 99), pp. 33-57.

13 Manuel Castells, "La era de la información" (Madrid: Alianza, 1977-1998). English ed.: The information age: economy, society and culture (Oxford: Blackwell, 1996). The same idea is also found in Mark Leonard, "Por qué Europa liderará el siglo XXI" (Madrid: Taurus, 2005), pp. 36-37. English ed.: 'Why Europe Will Run the 21st Century' (New York: PublicAffairs, 2005).
} 
nodes rather than parts, and they function openly and expansively. The structuring of organizations as networks creates a new dynamic of relations. Networks are open structures that are able to expand without limits, integrating new nodes provided that they can communicate with each other, i.e. provided that they share the same codes of communication. In the new dynamic there is no centre but there are clear results; there is no pre-established way of acting but merely an orientation towards the outcomes.

What I have called companionship has long been integrated in the techniques of management and team formation. However, though it is still important, it has not undergone major developments recently. On the other hand, what I have defined as collaboration has come to occupy a central position in the discourse among professionals. There are probably two reasons for this. The first concerns the complexity of the world and the changing role of librarians. Achieving the goals of an organization involves an increasing amount of interdisciplinary work. In libraries, the increase in functions (computer literacy, participation in the preparation of teaching materials, placing content online, etc.) has led to the incorporation of new professionals, and above all to an increase in collaboration with other university services. The second reason is the increasing importance of ICTs.

The English model of convergence of services is well known in Spain as an example of changes in the organizational environment of libraries brought about by internal collaboration, but in the US the model of convergence shows characteristics that are perhaps even more interesting. Universities there tend to have Chief Information Officers (ClOs)-managers who are generally responsible for 'information' in the university. Libraries are incorporated as services under the management of the CIOs or collaborate with them as organizations that manage and disseminate information.

On an international level, association was for many years the most visible 'relational' activity. It is still strong and has even been reinforced. The activity of national associations has been complemented by that of international associations. At a European level we should mention LIBER and the more specialized ELAG (for the application of ICTs to libraries), IATUL (for engineering libraries) and the European meetings of ICOLC (for consortia). However, the most important development in this area in the last few years has been cooperation through consortia.

The cooperatives of libraries and library networks that were set up in the 1970s in the USA, the UK and Holland were great examples of cooperation, but cooperation today carries the name of 'consortia'. These emerged in the late 1990s for the purpose of licensing electronic resources. ${ }^{14}$ They soon spread to almost all countries, and their activities developed from the licensing of contents to cooperative programs of all types (collective catalogues, digital repositories, training, etc.). These consortia have been superimposed on the earlier scenario of associations: they have not replaced them but

\footnotetext{
${ }^{14}$ William Gray Potter 'Recent trends in statewide academic library consortia' // Library Trends 45 (97) 3, 416-434. James J. Kopp / Library consortia and information technology: the past, the present, the promise // Information Technology and libraries 17 (98) 1, 7-12. G. Edward Evans / Management issues of cooperative ventures and consortia in the USA // Library management, Part 1.23 (02) 4-5, 213-226, Part 2. 23 (02) 6-7, 275-286.
} 
represent another means of increasing the power of libraries. They show that evolution is not only a question of growth but also one of increased complexity. They emerged in a mature situation when it was recognized that there was a threshold beyond which it was impossible to increase services within the limits of a single organization. Consortia are 'proximity' organizations: they are meaningful and operate well if they are near to libraries, so their geographic area (above all in large countries) is very often smaller than the state.

The world of alliances has always been a facet of the most active associations. When an association develops vigorously, it always reaches a border that it cannot cross alone. It is then interesting for the association to establish alliances with other associations with which it may have coinciding goals. For example, I consider the work of forming alliances ('lobbying') carried out in the UK by the Society of College, National and University Libraries (SCONUL) to be exemplary. Some recent 'problems' of university libraries (such as the intensive use of ICTs or the greater involvement of libraries in learning) cannot be approached in isolation but must be dealt with through alliances. Another important development is that in the last few years the international library movement has been very interested in establishing alliances with the archive and museum sectors.

Finally, one of the effects of the Internet has been an increase in cross-border relations. This has led to a resurgence of international associations, and also of the informal relations at a lower level that we have called fraternization. In the 21st century we are traveling and we will travel increasingly. Groups of libraries or individual libraries thus find it fairly easy to establish relations with others.

\section{Where we are}

We will now examine the situation of the Spanish university libraries with regard to the six relational categories established above.

Companionship is in a good state of health. The library managements that have been established since the mid-1980s, and particularly since the early 1990s, have focused on building teams and organizing the different libraries of universities as a whole. In view of the initial situation and the debates of the 1980s on centralization and decentralization In the early 1990s, it could not then have been foreseen that the result would have been as good as the one we now have. Library services have been consolidated as integral units in universities and their components (staff and institutions) consider themselves to form part of the whole.

It is difficult to obtain an accurate picture of the level of collaboration between Spanish university libraries and other university services. Despite the traditional isolation of libraries, several recent situations have forced them to establish links, for example, with quality units (as a result of assessments) or with teaching vice-rectorates (based on the REBIUN strategic plan that fosters the conversion of libraries into resource centers for learning and research). Significantly, whereas in the early 1990s it was the aspiration of library managers to report to the research vice-rectorate, our dependences and relations now cross the whole spectrum of services and activities of universities. Though libraries 
attain a high overall mark for collaboration, there is one partial examination that (perhaps with a few exceptions) they have clearly failed: relations with IT services. Libraries have far more in common with IT services than with many other services, but collaboration has not led to spectacular results. Library services are now highly technical, and their development depends on knowledge and infrastructures that we do not and cannot have in libraries. Our achievements in ICTs (and our success in this field) are based on the correct decision of Spanish university libraries to base their development on commercial applications and on concepts and programs from abroad that could be copied and/or installed without a great deal of support. Our capacity for innovation is reduced by the fact that we have failed to establish collaborations in this field.

The existence and activities of REBIUN have fostered the spirit of association in Spanish university libraries, but I feel that this area has two weaknesses. The first one is close to home, but nevertheless serious: the spirit of association in Spain is weak or at least it is not vigorous, and we find ourselves without allies in the library sector. Secondly, since the late 1980s REBIUN has devoted a great deal of time to its foundation, re-foundation and restructuring based on strategic planning. This-and a certain initial confusion between its (essential) role as an association and its (partially accepted) role as a network-have detracted from what could have been an excellent result. The best associations of the same nature as REBIUN devote a very large part of their time and activities to fostering debate and promoting the spirit of alliance.

Cooperation is represented in Spain by five established consortia and a few informal purchasing groups. ${ }^{15}$ To this we must add the cooperative project of DIALNET. The Spanish achievements in this area are not too different in scope and results from those of countries of similar characteristics and size, such as France, Italy, Germany and England. Insufficient attention has perhaps been paid to consortia, which have met with some resistance due to their nature as new organizations developing in a geographic area that does not coincide with the Spanish state. Seen perhaps as 'counterpowers', they have not been properly integrated as extensions of Spanish university libraries or used to extend the benefits of joint licensing of electronic resources to all Spanish libraries. The licensing of e-resources will in the near future go through the consortia, but its coordination with REBIUN should lead to benefits that will reach all university libraries. This will be achieved by extending the scope of the existing consortia, creating new consortia or setting up virtual consortia through aggregators.

From what has been said with regard to collaboration, it can be deduced that university libraries have not been very active in forming alliances. The most important alliance occurred when REBIUN became a sectoral commission of the Conference of Rectors of Spanish Universities (CRUE). However, perhaps understandably, sufficient advantage has not been taken of this opportunity to establish programs of joint action with other

\footnotetext{
15 Miquel Térmens Graells / Los consorcios, una nueva etapa de la cooperación bibliotecaria // El profesional de la información, 14 (05) 3, 166-173. Azucena Blanco Pérez / University libraries consortia in Spain // Serials 16 (03) 1, 53-55. Miguel Duarte Barrionuevo / New strategies in library services organization: consortia university libraries in Spain // Information Technology and libraries, 19 (2000) 2, 96-102. Lluís M. Anglada / Working together, learning together: the Consortium of Academic Libraries of Catalonia // Information technology and libraries, 18 (99) 3, 139-144.
} 
sectoral commissions on the subject of European credits, the development of ICTs, and information and guidance services for students. Among the alliances at this level we should include the relations established with organizations that have different natures and aims but partially coinciding objectives. The alliances with the Spanish Federation of Archival, Library, Documentation and Museology Association (FESABID) are the most natural and closest, but those that CODIBUCE initiated with the Ministry of Culture and with the Spanish academic telecommunication network and those on quality certification established with the national and federal agencies for the evaluation of quality of universities are also important.

The activity of fraternization has been and is still weak, at a time when it would be fully justified by the situation and the level of achievement of Spanish university libraries. ${ }^{16}$ The level of service has improved greatly in recent years and today Spain can establish relations in the European sphere on an equal footing. This does not, however, mean that we have nothing to learn from other organizations working in our environment. Spain and France are the major absentees from international forums. With a few honorable exceptions, European congresses are held without Spanish participation. On the other hand, the situation is not so bad in the professional literature because a group of university lecturers in this field have decided to present their publications to foreign journals in preference to Spanish ones.

\section{Future prospects}

Within the field of social intelligence, Spanish university libraries currently have three main strong points: they are well organized and coordinated within each university, REBIUN has been consolidated within the CRUE and has far-reaching action programs in place, and the existing consortia (with achievements that go beyond the licensing of contents) have potential to extend their benefits to all Spanish university libraries.

Perhaps the main weak point is the lack of IT support for developing innovative projects. Until we are able to establish effective collaborations within universities that allow us to keep up with the rate of technological progress and innovate in the provision of services, our efforts at renewal will show few results. There are three other weak points: the level of debate and exchange of information and ideas is lower than would be desirable, there is a lack of stable and powerful alliances that would allow us to achieve objectives more easily, and our international presence is lower than it should be.

More particularly, we believe that the enormous potential accumulated in recent years could be exploited more by reinforcing some actions in the relational sphere that could be developed in the next five years.

Companionship must continue the well developed path of forming teams and offering a view of university libraries as a whole. The leadership skills of library managers should be reinforced and management teams should be formed with potential for involvement in associations and cooperation on a second level. With regard to collaboration,

\footnotetext{
${ }^{16}$ We must, however, mention the presence of Spaniards in the university libraries section of the IFLA and the influence of the CBUC in the European ICOLC.
} 
university libraries should reinforce and improve any links that they may already have with other university services. The level of quality of the human teams of university libraries should make it possible to create a community of specialists acting as an observatory for the dissemination of best practices in these areas. With regard to associations, the path to follow is REBIUN, and more specifically its deliberative function of information exchange and lobbying. We should reinforce cooperation through consortia, on the understanding that they allow libraries to improve their services. We should also create a network of effective alliances according to the main lines of the future program of REBIUN, and including other library associations. By improving fraternization we could establish fairly stable links with a few selected associations of the same type. ${ }^{17}$ Finally, we should adopt a strategic goal of increasing Spanish presence in the main international forums that have the greatest affinities with Spanish university libraries.

In order to develop and improve the services we provide, librarians have always emphasized the need to increase resources or the use of technology. However, though these are important instruments of improvement, they are not the only ones. Above we mentioned the recent discoveries of psychology, and we can now make use of anthropology. The scientists working in this field state that the evolution of the human species has depended on both technological innovation and on our ability to 'socialize' invention. ${ }^{18}$ A technological advance is not introduced successfully at the first attempt: several attempts are necessary. In the course of this process, the innovation is refined, and it is finally introduced thanks to the work of social intelligence.

The improvements of Spanish university libraries in recent years have been widely recognized. The most obvious improvements in resources (buildings and technology) and services were achieved thanks to the right organizational decisions. In the future, in addition to resources, services and organization, the positive evolution of Spanish university libraries will be based on their capacity to create mechanisms of social intelligence.

\footnotetext{
${ }^{17}$ Such as SCONUL and the French Association of University Library Managers. Links with Portugal should be continued and increased, without excluding other links.

${ }^{18}$ Eudald Carbonell / Los sueños de la evolución (Barcelona: RBA, 2003), pp. 109-112.
} 